\title{
Antitumor Agents 278. 4-Amino-2H-benzo[h]chromen-2-one (ABO) Analogs as Potent In Vitro Anticancer Agents
}

\author{
Yizhou Donga ${ }^{a}$, Kyoko Nakagawa-Goto ${ }^{a}$, Chin-Yu Lai ${ }^{a}$, Susan L. Morris-Natschke ${ }^{a}$, Kenneth \\ F. Bastow ${ }^{b}$, and Kuo-Hsiung Lee ${ }^{a,{ }^{*}}$ \\ aNatural Products Research Laboratories, Eshelman School of Pharmacy, University of North \\ Carolina, Chapel Hill, North Carolina 27599-7568 \\ bDivision of Medicinal Chemistry and Natural Products, Eshelman School of Pharmacy, University \\ of North Carolina, Chapel Hill, North Carolina 27599-7568
}

\begin{abstract}
4-Amino- $2 H$-benzo[ $h]$ chromen-2-one (ABO) analogs were designed, synthesized, and evaluated for cytotoxic activity. Among all 4-substituted ABO analogs, cyclohexyl (12), $N$-methoxy- $N$ methylacetamide (14), and various aromatic derivatives (15-25 and 27) exhibited promising cell growth inhibitory activity with $\mathrm{ED}_{50}$ values of 0.01-2.1 $\mu \mathrm{M}$ against all tested tumor cell lines. The 4'-methoxyphenyl derivative (18) and 3'-methylphenyl derivative (24) showed the most potent antitumor activity against a broad range of cancer cell lines with $\mathrm{ED}_{50}$ values of 0.01-0.17 $\mu \mathrm{M}$. Preliminary SAR results indicated that substitutions on nitrogen are critical to the antitumor potency.
\end{abstract}

\section{Keywords}

4-Amino-2H-benzo[ $h]$ chromen-2-one analogs (ABO); cytotoxic activity; structure-activity relationships

\begin{abstract}
Natural products have been one of the most significant sources for drugs and drug leads. $1^{-3} 3$ In 2004, our group isolated a new compound, neo-tanshinlactone (1, Figure 1),4, 5 that showed potent anti-breast cancer activity. Our recent results proved that 4-ethyl neotanshinlactone (2) is a selective and potent in vivo anti-breast cancer agent in three different mouse models.6 In order to study the contribution of the individual rings of $\mathbf{1}$ and improve its pharmacological properties, we designed five different scaffolds, which led to the discovery and development of three series of novel anti-cancer agents: 2-(furan-2yl)naphthalen-1-ol (FNO), 6-aryl-4H-furo [3,2-c]pyran-4-one (AFPO), and tetrahydronaphthalene-1-ol (TNO) derivatives. $7^{-9}$ The promising results and useful information we obtained from these studies encouraged us to design and develop additional novel anti-cancer agents based on $\mathbf{1}$.
\end{abstract}

\footnotetext{
(C) 2010 Elsevier Ltd. All rights reserved.

“Corresponding author. Tel: 919-962-0066; fax: 919-966-3893; khlee@unc.edu .
}

Supplementary data Supplementary data [spectroscopic data for 9-31 and statistical analysis (standard deviations) for cytotoxicity data] associated with this articles can be found in the online version.

Publisher's Disclaimer: This is a PDF file of an unedited manuscript that has been accepted for publication. As a service to our customers we are providing this early version of the manuscript. The manuscript will undergo copyediting, typesetting, and review of the resulting proof before it is published in its final citable form. Please note that during the production process errors may be discovered which could affect the content, and all legal disclaimers that apply to the journal pertain. 
Structural simplification and bio-isosteric replacement are powerful and highly productive tools for analog design and drug development.10 In our continuing studies, we combined these two strategies to further explore the structure of $\mathbf{1}$ and develop more potent analogs. Previously, we designed a simplified scaffold $\mathbf{3}$ by breaking the furan ring-D (Figure 1);7 however, this compound series did not show significant anti-cancer activity. We then designed scaffold $\mathbf{4}$ (ABO), by replacing the oxygen in 3 with nitrogen. Braccio et al. reported numerous pyran derivatives, including four compounds with this scaffold, which showed activity against Ehrlich ascites tumor cells.11 These positive results supported our design and investigation of this scaffold. We introduced different substituent groups around the skeleton of $\mathbf{4}$ to establish preliminary SAR and develop more potent analogs. Because our prior study showed that $\mathbf{2}$-analogs with an ethyl group at the C-4 position possessed much higher potency than 1-analogs with a hydrogen at the same position (Figure 1), we also evaluated the effect of an ethyl group $\left(\mathrm{R}_{1}=\mathrm{Et}\right)$ in the corresponding position (C-7) in 4. This paper reports the synthesis of novel ABO analogs, discovery of new analogs with potent antitumor activity, and identification of preliminary SAR.

All target compounds 9-31 were synthesized from 4-hydroxybenzochromenones $\mathbf{5}$ and $\mathbf{6}$ (Scheme 1). 4 Treatment of $\mathbf{5}$ and $\mathbf{6}$ with $\mathrm{POCl}_{3}$ afforded the related chlorides $\mathbf{7}$ and $\mathbf{8}$, respectively.11 Differently substituted amino groups were then incorporated to study the effect of position, hydrogen bond donor or acceptor, and group size. Compounds, 9-10, 13-14, and 16-31 were newly prepared by substitution reaction of the chloride in 6 or 7 with various amines according to reported procedures.11, 12 Compounds 11, 12, and 15 were previously synthesized by Braccio's group. 11

All synthesized analogs 9-31 were tested for in vitro cytotoxic activity against a panel of human tumor cell lines according to previously published methods (Table 1).7 Cell lines included A549 (non small cell lung cancer), DU145 (prostate cancer cell line), KB (nasopharyngeal carcinoma), and KB-vin (vincristine-resistant MDR KB subline), MDAMB-231 (estrogen receptor negative breast cancer), SK-BR-3 (estrogen receptor negative, HER2 over-expressing breast cancer), ZR-75-1 (estrogen receptor positive breast cancer). While the parent compound, 1, displayed selective activity against SK-BR-3 and ZR-7-51 breast cancer cell lines, $\mathrm{ABO}$ analogs showed a broad activity spectrum against all seven cancer cell lines tested.

Concerning analogs with aliphatic $\mathrm{R}^{2} / \mathrm{R}^{3}$ amino substituents, $\mathbf{1 2}$ with a cyclohexyl group showed much higher activity than the methyl, propyl, and cyclopropyl derivatives 9-11, which suggested a bulky amino group is favored. The tertiary amines 28-30 were essentially inactive; thus, the secondary amine could play a critical role in the antitumor activity. The $\mathrm{NH}$ might act as a hydrogen bond donor, which can be important to ligand-receptor interaction. Compounds 14 with an $N$-methoxy- $N$-methylacetamide group and 13 methyl acetate group were between 3- and 60-fold more potent depending on the cell lines tested, respectively, than $\mathbf{1 0}$ with a propyl group. These results suggested that a hydrogen bond acceptor may be favored in this side chain.

Concerning aromatic $\mathrm{R}^{2} / \mathrm{R}^{3}$ substitutents, most aromatic derivatives, regardless of the position and type of functional group on the phenyl ring, showed significant cytotoxicity with $\mathrm{ED}_{50}$ values of 0.01-2.1 $\mu \mathrm{M}$. The only exception was the 3'- $\mathrm{Br}$ analog, 26, which dramatically lost inhibitory activity and suggested that halogen may not be favored at this position. Among all aromatic derivatives, 15-27, 4'-MeO analog 18 and 3'-Me analog 24 were the most potent against all tested tumor cell lines $\left(\mathrm{ED}_{50}\right.$ values of $\left.0.01-0.17 \mu \mathrm{M}\right)$. Naphthyl analog 27 also displayed potent activity $\left(\mathrm{ED}_{50}=0.27-0.53 \mu \mathrm{M}\right)$. These results may indicate that an aromatic group is suitable to fit into the binding pocket of the target protein, resulting in potent activity. 
We also investigated the difference between hydrogen and ethyl as the $\mathrm{R}^{1}$ substituent by comparison of $\mathbf{1 4}$ and 31, respectively. Compound $\mathbf{1 4}$ was 5- to 38 -fold more potent than the related $\mathrm{R}^{1}$-ethyl analog, 31. Thus, hydrogen is favored over ethyl in ring- $\mathrm{A}$, which contrasts with the SAR of $\mathbf{1}$-analogs. Moreover, $\mathbf{1 4}$ displayed broader antitumor activity compared with $\mathbf{1}$, which could suggest a different mechanism of action. Interestingly, analog $\mathbf{3 0}$ showed unique selective activity against the $\mathrm{ZR}-75-1$ cell line $\left(\mathrm{ED}_{50}=3.9 \mu \mathrm{M}\right)$ compared with other tested cell lines $\left(\mathrm{ED}_{50}>30 \mu \mathrm{M}\right)$.

In conclusion, we designed 4-amino- $2 H$-benzo[ $h]$ chromen-2-one (ABO) analogs by structural simplification and bio-isosteric replacement of neo-tanshinlactone (1), and investigated in vitro antitumor activity. The results indicated that ring-D of $\mathbf{1}$ is critical to both potency and tumor-tissue selectivity. Based on this study, a novel class of anti-cancer agents, ABO derivatives, was discovered and preliminary SAR around this scaffold was established as follows: (1) secondary amine $\left(\mathrm{R}^{2}\right.$ or $\left.\mathrm{R}^{3}=\mathrm{H}\right)$ is preferred over tertiary amine $\left(\mathrm{R}^{2}\right.$ and $\mathrm{R}^{3} \neq \mathrm{H}$ ); (2) bulky groups are favored at $\mathrm{R}^{2} / \mathrm{R}^{3}$ position; (3) 3'-bromo phenyl group can cause dramatic loss of potency and (4) at $\mathrm{R}^{1}$ position, a hydrogen is better than an ethyl group. Compounds $\mathbf{1 8}$ and $\mathbf{2 4}$ were the most potent analogs $\left(\mathrm{ED}_{50}\right.$ values of 0.01 and 0.08 $\mu \mathrm{M}$, respectively, against the ZR-7-51 cell line), and showed broader antitumor activity compared with 1 . Mechanism of action studies are ongoing and progress will be reported in due course. In summary, $\mathbf{1 8}$ and $\mathbf{2 4}$ are promising new lead compounds for further development toward a potential clinical trials candidate.

\section{Supplementary Material}

Refer to Web version on PubMed Central for supplementary material.

\section{Acknowledgments}

This work was supported by NIH grant CA-17625 from the National Cancer Institute, awarded to K.H. Lee.

\section{References}

1. Vuorelaa P, Leinonenb M, Saikkuc P, Tammelaa P, Rauhad JP, Wennberge T, Vuorela H. Curr. Med. Chem. 2004; 11:1375. [PubMed: 15180572]

2. Saklani A, Kutty SK. Drug Discov. Today. 2008; 13:161. [PubMed: 18275914]

3. Rishton GM. Am. J. Cardiol. 2008; 101:43D. [PubMed: 18243858]

4. Wang X, Bastow KF, Sun CM, Lin YL, Yu HJ, Don MJ, Wu TS, Nakamura S, Lee KH. J. Med. Chem. 2004; 47:5816. [PubMed: 15509181]

5. Wang X, Nakagawa-Goto K, Bastow KF, Don MJ, Lin YL, Wu TS, Lee KH. J. Med. Chem. 2006; 49:5631. [PubMed: 16942038]

6. Dong Y, Shi Q, Pai HC, Peng CY, Pan SL, Teng CM, Nakagawa-Goto K, Yu D, Liu YN, Wu PC, Bastow KF, Morris-Natschke SL, Brossi A, Lang JY, Hsu JL, Hung MC, Lee EY, Lee KH. J. Med. Chem. 2010; 53:2299. [PubMed: 20148565]

7. Dong Y, Shi Q, Liu Y-N, Wang X, Bastow KF, Lee KH. J. Med. Chem. 2009; 52:3586. [PubMed: 19425534]

8. Dong Y, Shi Q, Nakagawa-Goto K, Wu PC, Bastow KF, Morris-Natschke SL, Lee KH. Bioorg. Med. Chem. Lett. 2009; 19:6289. [PubMed: 19819136]

9. Dong Y, Shi Q, Nakagawa-Goto K, Wu PC, Morris-Natschke SL, Brossi A, Bastow KF, Lang JY, Hung MC, Lee KH. Bioorg. Med. Chem. 2010; 18:803. [PubMed: 20034799]

10. Wolff ME. Burger's Medicinal Chemistry and Drug Discovery (fifth ed). 1994; Vol. 1:1064.

11. Di Braccio M, Grossi G, Roma G, Marzano C, Baccichetti F, Simonato M, Bordin F. Pyran derivatives. Part XXI. Antiproliferative and cytotoxic properties of novel N-substituted 4- 
aminocoumarins, their benzo-fused derivatives, and some related 2-aminochromones. Farmaco. 2003; 58:1083. [PubMed: 14572859]

12. Alberola A, Alvaro R, Ortega AG, Sadaba ML, Sanudo MC. Synthesis of [1]benzopyrano[4,3b]pyrrol-4(1H)-ones from $\mathrm{N}(\alpha)$-(2-oxo-2H-1-benzopyran-4-yl)weinreb $\alpha$-aminoamides.

Tetrahedron. 1999; 55:13211. 


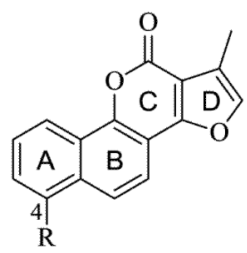

$\mathrm{R}=\mathrm{Me}:$ Neo-tanshinlactone $(\mathbf{1})$

$\mathrm{R}=$ Et: 4-Ethyl neo-tanshinlactone (2)

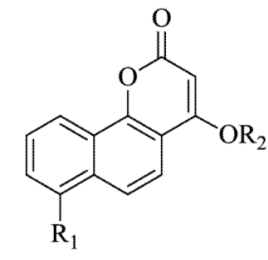

3

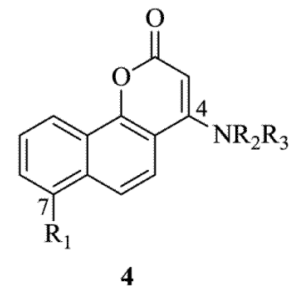

4

Figure 1.

Structures of neo-tanshinlactone (1), 4-ethyl neo-tanshinlactone (2), previously reported scaffold $\mathbf{3}$, and newly designed scaffold $\mathbf{4}$ 

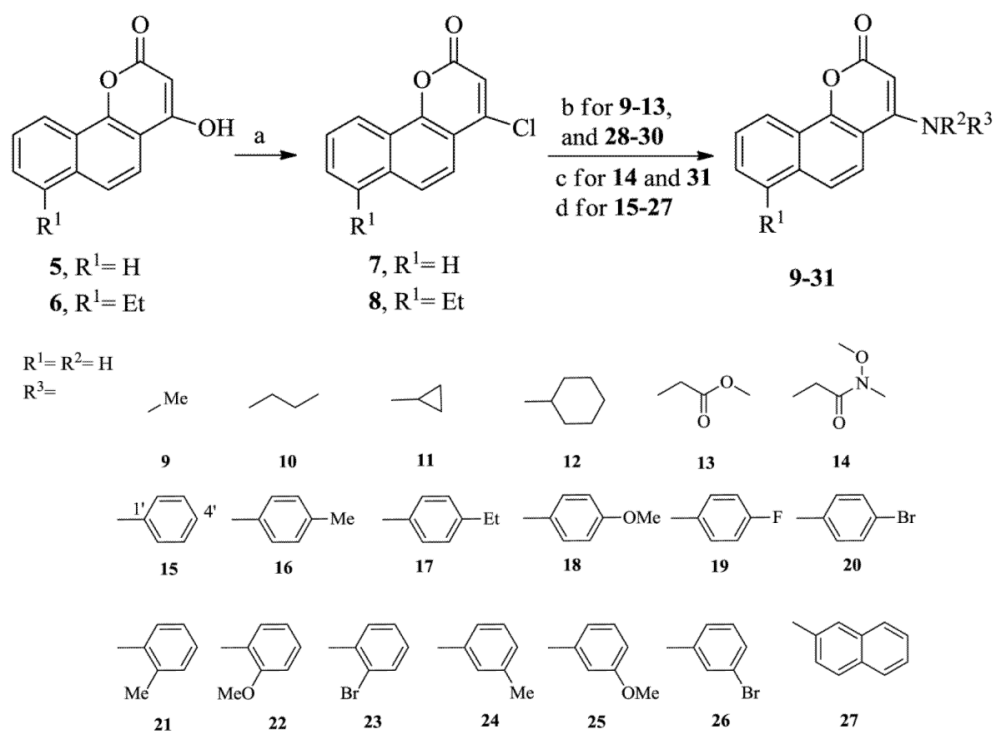

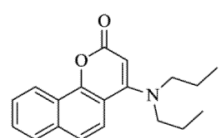

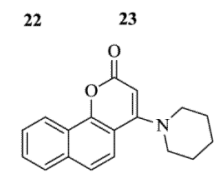

29
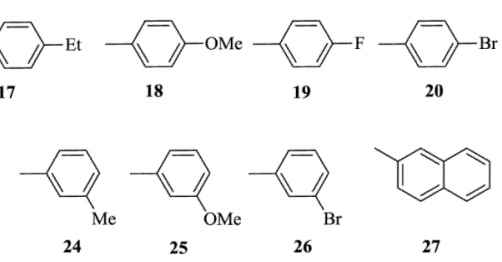

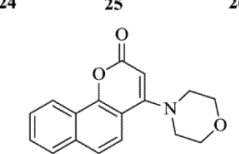

30

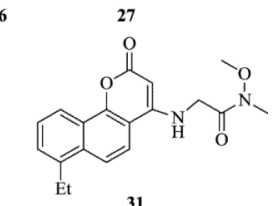

Scheme 1.

Reagents and conditions: (a) $\mathrm{POCl}_{3}, \mathrm{Et}_{3} \mathrm{~N}$, reflux, $1 \mathrm{~h}$; (b) aliphatic amines, EtOH, reflux, 2h; (c) 2-amino- $N$-methoxy- $N$-methylacetamide hydrobromide, $\mathrm{Et}_{3} \mathrm{~N}, \mathrm{EtOH}, 55^{\circ} \mathrm{C}$; (d) aromatic amines, ethylene glycol, $160{ }^{\circ} \mathrm{C}, 1 \mathrm{~h}$. 


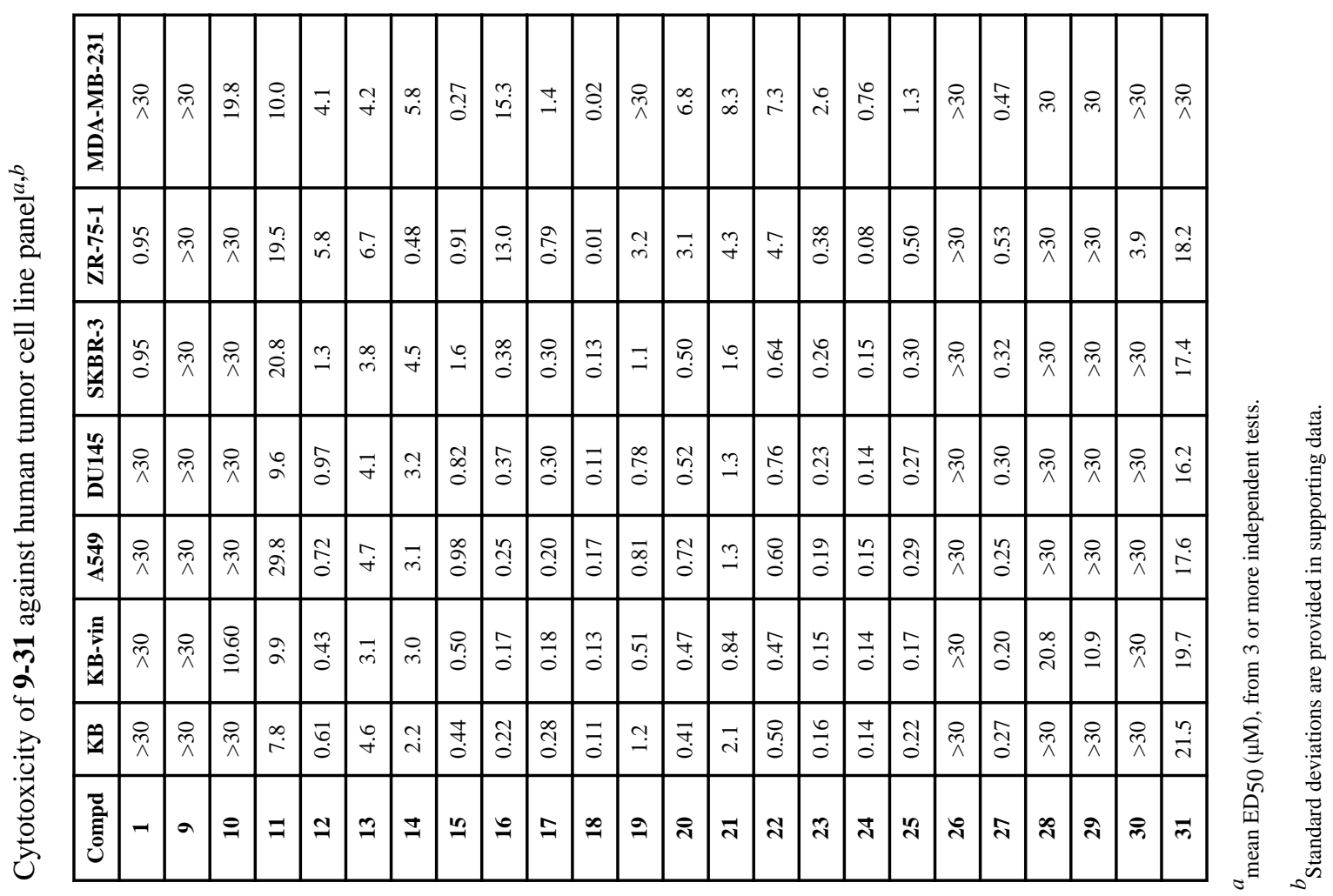

